\title{
Brief Talk about the Application and Development of Coal Mine Machinery
}

\author{
Yu Zhao \\ Sichuan Fine Arts Institute, Chongqing, 401331, China
}

\begin{abstract}
Keywords: Coal Mining machinery. Application. Development
\end{abstract}
\begin{abstract}
The rapid progress of our country science and technology speeds up the development process of our country's industrialization. More recently, mechanization level of coal mining in our country is higher and higher; however, due to the short history of coal mining mechanization development in our country, there are still a lot of problems. This paper first introduces the technology application of finite element method, the CAD technology, green design and optimization design in coal mine machinery, , secondly introduces the current status where intellectualization of coal mine machinery is low, with serious pollution and large volume, finally, introduces the development of the supervisor technology to coal mine machinery operating mode , the development of integration technology of machine battery solution , and the trend of development of intellectualization, automatization, modernization and localization of manufactures.
\end{abstract}

\section{The mechanization development of coal mine}

The unceasing progress of society and the booming development of economy accelerate the era in which machinery substitutes the handicraft industry, and coal mine of our country has made notable result after previous decades of development, but there appear still more or less inevitable problems to be badly needed. The restriction of the existing technology leads to the bulkiness of most of the coal mining equipments, which are modeled uniformly according to most terrain and geological conditions, therefore incapable to manipulate smoothly. The excessive bulkiness of the coal mining equipment depressed greatly the work efficiency of coal mining, thus degreased the productivity of coal mining enterprises. At present, our country has stepped up the efforts to speed up the development of coal mining machinery, which has gradually developed from former single function to the comprehensive functions; therefore work efficiency of the coal mine is greatly improved, in addition, save human resources to a certain degree. Our country has gradually made progress of coal mine equipment mechanization, so as to promote the further development of the coal mining enterprises.

\section{The technical application of coal mine machinery}

The application of finite element method (fem)

Finite element method (fem) is a highly efficient and commonly used calculation method, which can discretize the continuous solution domain and then generate an aggregate of a set of units, where, the unknown field function to be obtained in the solution domain is represented by lamination of approximate function assumed in the unit, and the approximate function is represented by unknown field function and difference functions of derivative in each node within the unit, thereby it transforms the continuous problem of infinite degrees of freedom to discrete finite degrees of freedom. Finite element method can not only be appropriate for some dynamic analysis and static problem, but also can solve the static problems and unsteady state encountered in the project. The ANSYS and i-deas used widely all belong to mature large finite element software. And the stress of the coal mine machinery is more complex, which is just in line with the applicable conditions of the finite element method, therefore, in the design of coal mine, the crossbeam in its supporting tank device, in order to determine its conditions for acceptance, and analyze visually its weak link . 


\section{The application of CAD technology}

CAD is a computer aided technology, and can use the computer hardware system to design and provide assistance, such as engineering analysis, drawing and document production and design, and so on. At present, the product coal mine machinery products have tended to be mature, and the wide use of CAD technology in coal mine machinery, can realize the modular design of mechanical products and the integration design of CAD technology , CAPP and CAM design, so the product model existed in the computer can enter directly CAPP, through the complete technological design , layout and NC programming, the processing code generated from it can be transmitted into the NC machine tool, machining center, and the whole form processing, the use of CAD technology in coal mine machinery link the two segments more closely, shortening the production cycle of the products whole form processing and computer products to a certain extent, thereby improving the production efficiency of products, which testifies that the use of CAD technology in coal mine machinery can notably enhance the auxiliary benefit of the computer.

\section{The application of the green design technology}

The application of the green design technology is an important way of promoting the sustainable development of coal mine machinery, it focuses on environment protection, thoroughly implement and realize the green concept throughout the product planning and design, connect the base attribute of the products and environment attribute closely throughout the entire production cycle, and meet the environmental goals of the product based on the meeting the physical objective, thereby reach the optimization design of the product .. During the green design of coal mine machinery, we should ensure that the products are environmentally friendly, minimize their pollution and damage of the environment. During the product design, simplify the product structure as much as possible; decrease the wasting of resources, and pay attention to the recycling of the materials, thereby saving resources, minimizing the energy consumption in the coal mine machinery design.

\section{The application of the optimization design technology}

Optimization design refers to that converting the problems encountered in engineering design of mathematical model based on the codes and standards established by state, and based on general design idea and design method, and then find the optimal design proposal in the diversified programs established using the computer network technique and optimizing the design technique Optimization design can not only improve production quality, improve the level of the product design, but also can promote the role of computer aided design. The use of optimization design in the coal mine machinery design similarly enhance the planning level of products and production quality, and use the optimization design as early as possible in the design period, because the early use of the optimization design can embody the advantage that the optimization design bring the product design and design quality..

\section{The present situation of our coal mine machinery}

\section{Equipment intellectualization is low}

Although our country has preliminarily realized the mechanization of coal mine machinery, but its mechanization level is still far behind, and still belongs to the development mode of extension type. Today's society combines the digitization and intellectualization, always sticking to the science and technology as primary productive forces. The international science and technology competition currently lead to the higher requirement to the digitization, modernization and intellectualization. Mechanical equipment and produced quantity of the coal mine in our country proved to be the first based on the data, however, the digitization and intellectualization of our coal mine machinery fall far behind the world, restricting the modernization development of the coal mine, and mechanism control and mechanical power still dominate most coal mine mechanical equipment, therefore lead to the low intellectualization, impacting the productivity of our coal mine. 


\section{The Pollution is more serious in coal mine machinery}

Although our country has preliminarily applied the green design to the coal mine machinery, the pollution of coal mine machinery and energy consumption problems were more significant which is related closely with the environmental factors such as ground, water and air during the recovery process of coal mine, it's necessary to consider the environmental pollution and energy consumption in the coal mine machinery. In the future mechanical design, we should comprehensively consider the energy saving of coal machinery, recovery and recycling after the scrap of the products, the impact of the disposal of the rejected material on the environment during the production process.

\section{The volume of coal mechanical equipment is too large in volume and bulky}

One of the characteristics of the coal mechanical equipment is its oversize in volume and bulky. The oversize and bulkiness of the Coal mechanical equipment lead to the least flexible operation of the machinery, and restrict the relocation of the coal machinery equipment to a certain extent, consequently affecting the production efficiency of the coal mine. Oversize and bulkiness of Coal mechanical equipment also increase the energy consumption, shorten the service life, and make a machine be difficult to adapt to a variety of geological conditions and production conditions of the mine. The vulnerableness of domestic machinery greatly reduced the integrity of the mechanical equipment, decreasing greatly the reliability of the mechanical equipment, it's necessary to maintain and replace the mechanical equipment periodically, depressing the productivity of the coal mine , its safety performance, and shelf life of the equipment .

\section{The development of coal mine machinery}

\section{The development of supervisor technology of coal mine machinery}

The development of monitoring technology in coal mine machinery condition make the judgment possible that the operational state of coal mine is abnormal or not, consequently realizing the vibration monitoring of coal mine machinery based on the frequency domain of the vibration signal during the operation of the coal mine mechanical equipment, time-domain specification and variance and rules in characteristic value At the same time the man-machine dialogue, automatic alarm and automatic control function can be realized based on the real-time monitoring of coal mine machinery condition and the diagnosis with the equipment abnormality. The technology can be used to study the hydraulic pressure of machinery, abrasive dust in the specimen extracted in the lubrication system, making clear the abrasion state of the components of mechanical equipments. And the technology can also detect the crackle and damage in the components in the mechanical equipment by supersonic method and magnetic powder, and then judge where the crack generates and its faulted condition. You can also monitor the current and voltage of electric equipment.

\section{The development of the integration of the machine battery solution}

An important symbol in the future development of coal mine machinery equipment is the realization of integration technology of the machine battery solution. The technology of integration of the machine battery solution is an optimal system comprised of electronic information, machinery and hydraulic system and some correlation technique and its theory, which is an oncoming synthetic high tech technology, can realize the high integration of electric components and parts and machinery, and can make the mechanical operation self regulated and self induced.

The development of the intellectualization, digitization, modernization and localization

Intellectualization, digitization and modernization are overall trend of development of the contemporary science and technology, for which the coal industry must adapt if it wants to achieve long-term development in the fierce market competition and energy competition, and continuously introduce the advanced equipment and technology, gradually realizing the intellectualization, digitization and modernization of mechanical operation mode, making the coal machine not only improve the production efficiency, but also reduce a lot of administrative personnel, consequently decreasing the equipment cost of the enterprises, shake off the conditionality brought about by foreign technology, moreover, homemade mechanical equipment be more able to adapt to Chinese geological conditions and conditions of the mine, making its use effect greatly increased. 


\section{Conclusion}

With the continuous development of science and technology, a large number of new and high technology appeared, there are a lot of problems during the use of coal mine machinery in our country, we should continuously introduce the new science and technology, promoting the improvement of the mechanization level of our country, high and new technology is the trend of development of our coal mine, the unceasing innovation of technology is the valuable approach for our coal industry to take a place in the drastic market competition, the future of the coal mine machinery will inevitably the development path of Scientification.

\section{References}

[1] Yang Yunfeng, Song Yifu: The application of modern design methods in the design of Colliery Mechanical \& Electrical products, Zhongzhou coal, 2005 (2): 25-26.

[2] Kang Jianan: The current status and trend of development of coal mine machinery in our country, Shanxi coal, 2005, 25 (2): 32-33.

[3] Li Youzhong: Brief talk about the technological innovation and reliability enhancement of coal mine machinery in China, mechanical engineering and automation , 2008, 6 (3) : 199. 